\title{
LETRAMENTO E PROCESSO DE ESCRITURA DE ALUNOS RECÉM-ALFABETIZADOS
}

Eduardo CaliL

Kall Anne Amorim*

LIDIANE LiRA ${ }^{* * *}$

\begin{abstract}
RESUMO: A partir de um enfoque genético (Genética de Textos) e enunciativo, este trabalho discute como elementos lexicais, semânticos e sintáticos relacionados ao letramento escolar interferem na criação de títulos de contos etiológicos inventados por escreventes novatos (6 a 7 anos). Nosso corpus foi coletado durante o desenvolvimento de um projeto didático de Língua Portuguesa, realizado numa escola de Maceió em 2012. Selecionamos como objeto de análise o processo de escritura de um título produzido por uma díade de alunos, quando a professora solicitou a invenção de um conto de origem. Nossa análise destaca tanto a relevância da leitura deste gênero para a estruturação do título dado, quanto a importância do processo coenunciativo (e intersubjetivo) que deu visibilidade ao material linguístico advindo do trabalho com o livro didático de Ciências.
\end{abstract}

Palavras-chave: Escola. Letramento. Manuscrito. Criação. Enunciação. Título.

* Doutor em Linguística e professor associado do Centro de Educação da Universidade Federal de Alagoas (Ufal).E-mail: eduardocalil@hotmail.com

** Doutoranda do Programa de Pós-Graduação em Educação da Universidade Federal de Alagoas (Ufal). E-mail: kallanneamorim@gmail.com

*** Doutoranda do Programa de Pós-Graduação em Educação da Universidade Federal de Alagoas (Ufal) e professora substituta da Universidade Estadual de Alagoas (Uneal).

E-mail: libidilira@gmail.com

Cad. Cedes, Campinas, v. 33, n. 89, p. 73-89, jan.-abr. 2013

Disponível em <http://www.cedes.unicamp.br> 


\section{LITERACY AND WRITING PROCESS OF NEWLY LITERATE STUDENTS}

ABSTRACT: This study is inserted in the field of Textual Genetics and Enunciation Linguistics studies and discusses how lexical, syntactic and semantic elements related to school literacy interfere in the creation of titles for etiological tales invented by novice writers (6 to 7 years old). Our corpus was collected during the development of a didactic project for the teaching of Brazilian Portuguese, held at a school in Maceió in 2012. As the object of analysis we selected the process of writing a title produced by a pair of students, when the teacher asked them to invent an origin tale. Our analysis highlights both the importance of reading this genre for structuring the given title and the co-enunciative (and intersubjective) process that foregrounded the linguistic material arising from work with the Science textbook.

Key words: School. Literacy. Writing. Manuscript. Creation. Enunciation. Title.

\section{Introdução}

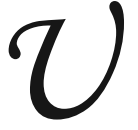

m significativo número de estudos discute a produção de texto em sala de aula, relacionando-a com o contexto letrado. De modo geral, no Brasil, podemos dizer que há um consenso entre os trabalhos deste campo, tanto do ponto de vista científico (SOARES, 2004; KLEIMAN, 1995; ROJO, 1998), quanto didático-curricular (BRASIL, 1997, 2007a, 2007b), sobre a importância da qualidade e representatividade do material textual que entorna o aluno (em casa e na escola), para estabelecer situações de aprendizagem adequadas ao seu desenvolvimento como escrevente.

Ainda que o letramento possa estar associado a diferentes objetos e disciplinas, apresentando um amplo leque de definições, a sua relação com a escola - mediada através de práticas discursivas diversas, mas, sobretudo, aquelas de caráter didático - traz a necessidade de entendermos como estas práticas interferem no processo de escritura em sala de aula.

Uma das primeiras publicaçôes da década de 1980, reunindo artigos sobre o trabalho com o texto na sala de aula (GERALDI, 1984), já defendia que as condições de produção oferecidas pelo professor são determinantes para a qualidade do texto produzido pelo aluno. A esta 
publicação seguiram-se muitas outras em que se indica o papel do outro como elemento constitutivo do processo de escritura (GARCEZ, 1998; MATENCIO, 1994; SAUTCHUK, 2003). Dessa perspectiva assumidamente sócio-histórica (BAKHTIN, 1992), o letramento não pode ser dissociado da noção de alteridade que funda a relação do sujeito falante (DUFOUR, 1990) com o mundo que o cerca. O acesso ao universo letrado seria possível somente através da interação verbal e suas práticas que irão constituir tanto a memória do objeto (AMORIM, 2009), quanto amemória do aluno-escrevente (CALIL, 2012a).

Sendo o manuscrito escolar o objeto de estudo privilegiado pela maioria daspesquisasdeste campo investigativo, muitos autores advogam a diversidade de gêneros textuais como sendo basilar para as práticas discursivas e comunicacionais contextualizadas e significativas. Isso significa dizer que a presença de textos representativos socialmente e sua recepção pelos alunos seria um dos fatores determinantes para sua entrada no universo da escrita, ainda que ele não esteja alfabetizado.

Apesar da relevância da presença de gêneros textuais para o ensino da leitura e escrita, o modo de apropriação de um texto lido não pode ser tomado como equivalente ao processo de escritura textual; o texto pronto indica apenas a ponta do iceberg, escondendo o que foi seu processo de escritura em tempo real. Além disso, o escrevente novato não se encontra, evidentemente, na mesma posição do escrevente experiente.

$\mathrm{O}$ manuscrito produzido em sala de aula pode trazer, a partir de seus elementos linguísticos, algumas marcas do processo de letramento, mas não permite analisarmos o que se passou durante seu processo de escritura e criação: que ideia surgiu em um primeiro momento, foi abandonada e depois retomada? De que modo o conhecimento que se tem sobre o gênero textual a ser escrito interfere no processo em tempo real de sua escritura?

Estas questōes referentes ao "texto que está se fazendo" tem sido o ponto central de nossos estudos (CALIL, 2008, 2009). Tendo-as por pano de fundo, analisaremos o momento em que uma díade de alunos recém-alfabetizados elabora o título de um conto etiológico. Anterior à análise, situaremos o quadro teórico que nos serve de fundamentação e, em seguida, detalharemos os procedimentos utilizados para a coleta deste dado. 
Processo de escritura em alunos recém-alfabetizados

Ao elegermos este momento do desenvolvimento infantil como objeto de estudo, pretendemos entender como o processo de escritura em tempo real, efetivado na sala de aula,caracteriza-seem condiçôes in natura e in locus. Em particular, ao colocarmos em destaque o contexto letrado e suas relaçôes com o processo de escritura, objetivamos ter algum acesso ao conhecimento do aluno recém-alfabetizado, a partir do que é recuperado e integrado no momento da configuração do manuscrito de um determinado gênero textual.

\section{Letramento, cognição, alteridade e figura de texto}

O campo de estudo constituído pelas investigaçóes dedicadas a compreender os processos de escritura, capitaneados pela Psicologia Cognitiva, mostra a complexidade deste ato, envolvendo não só a maturação motora do escrevente e a instrução recebida, mas também o longo tempo de prática que seu aprendizado exige para se escrever bem (KELLOGG, 2008; MCCUTCHEN, 2011).

Dada a capacidade limitada da memória de trabalho (MCCUTCHEN, 2000), o escrevente pouco experiente ainda não consegue articular conteúdo e processo, escrevendo aquilo que primeiro se recupera da memória de longo prazo. Ou seja, neste momento inicial não é possível, do ponto de vista cognitivo, fazer com que conteúdos, elementos linguístico-discursivos e propriedades textuais sejam intensamente ou significativamente retomados e reformulados. Quando as reformulaçóes acontecem na escritura, elas incidem majoritariamente em pontos locais e estão relacionadas às instruções recebidas (BEREITER; SCARDAMALIA, 1987), havendo ainda poucas revisões de sua unidade textual global.

Certamente, o processo de criação textual em alunos recém-alfabetizados não está restrito ao funcionamento cognitivo, mas engloba o universo letrado e as práticas discursivas instanciadas tanto através das interações com familiares e professores, quanto através do acesso aos gêneros adequados à faixa etária, sobretudo aqueles caracterizados pelas narrativas ficcionais e poesias infantis, veiculados através de livros, gibis, livros didáticos, $\mathrm{CD}$ e DVD, videogames, televisão e suportes tecnológicos diversos. Partimos da hipótese de que a riqueza deste universo e destas práticas irá constituir 
a dimensão simbólico-imaginária (e, portanto, subjetiva) do escrevente e suas "figuras de Texto", tendo como base a memória social e cognitiva do escrevente novato.

Como temos defendido em Calil (2010), a figura de Texto, conceito derivado da noção "figura de Outro" (DUFOUR, 2005, p. 37), delimita as relações de alteridade e permite a configuração do manuscrito. O escrevente novato, imerso em um amplo universo letrado, traz uma multiplicidade de elementos linguísticos e discursivos a serem rearranjados e combinados durante seu processo escritural. Esse rearranjo, apesar de estar limitado cognitivamente, tem seu caráter imprevisível e singular, sendo estabelecido pelos universos textuais e restrições imaginárias que cristalizam certas formas de dizer. É nesse sentido que entendemos o termo "configuração", isto é, aquilo que é dado sócio-historicamente como textoe tem por função fazer "semblante" ("unidade") para o escrevente novato, delimitando o que pode ou não pode fazer parte do que se está escrevendo.

O aluno, ao assumir esta posição de escrevente, atualiza o conhecimento resultante das práticas discursivas constituídas em seu contexto interacional e letrado. As figuras de Texto materializadas em seu manuscrito são determinadas duplamente: os elementos sintáticos, semânticos, lexicais, textuais e discursivos que se repetem nestas práticas discursivas vivenciadas e o rearranjo desses elementos postos em articulação por uma posição subjetiva, singularizando o que é da ordem da repetição. Daí considerarmos a repetição, e suas relações em paralelo, como elementos centrais na constituição de subjetividade do escrevente. Esses fenômenos instauram não só um imaginário que figurará como valor de "texto", mas, sobretudo, as relações de alteridade que fundam a condição de sujeito falante e, em particular, o próprio ato de escritura.

\section{Manuscrito escolar e sua dimensão genética}

Os múltiplos fatores (sócio-históricos, pragmáticos, comunicacionais, tecnológicos, interacionais, linguísticos, cognitivos, discursivos, textuais, gráficos...) relacionados às condiçōes de produção e aos processos de criação textual em contextos escolares não podem ser desconsiderados na análise da gênese de manuscritos escolares. Nosso interesse pelo "processo de criaçãa" exige, portanto, alguma pontuação sobre o que entendemos por esta expressão. Ela comporta, ao menos, dois sentidos. De um lado, 
a dimensão "genética", relacionada aos caminhos, traços, pistas, rasuras deixadas ao longo do "processo" de escritura, tanto do ponto de vista sincrônico (aquilo que acontece durante o ato escritural), quanto diacrônico (relações entre manuscritos de um mesmo escrevente). De outro lado, o sentido de "criatividade" suposto em "criação textual". Neste momento, e em função de nossos propósitos, é suficiente dizer que a "criatividade" seria o surgimento de uma nova ideia, a partir da combinação de diferentes elementos herdados.

Manteremos a mesma linha argumentativa apresentada em trabalhos recentes (CALIL, 2010, 2012a, 2012b), mostrando como o acesso à cultura escrita (e escolar) pode favorecer o processo de criação textual, fornecendo elementos linguístico-discursivos de diferentes níveis (morfossintáticos, semânticos, textuais...). Como não é possível, dentro dos limites deste artigo, analisarmos a integralidade do complexo processo de escritura de um manuscrito, discutiremos a gênese e a criação do título de um conto etiológico dado por uma díade de escreventes novatos.

\section{Metodologia}

O corpus de análise foi obtido através do desenvolvimento do projeto didático "Contos do como e do por que", envolvendo a leitura e a escritura de contos etiológicos. Ao longo de quatro meses (março a junho de 2012), a professora de um $2^{\circ}$ ano do ensino fundamental da Escola Criar e Recrear ${ }^{1}$ (Maceió) leu aproximadamente quarenta contos, reescreveu coletivamente o conto "Festa no céu" (BRAGUINHA, 2009) e propôs a produção de 12 contos inventados, ora sugerindo algum título, tema ou personagens (cinco propostas), ora deixando o "tema livre" (sete propostas).

Buscando respeitar algumas das características de uma metodologia etnográfica, tentamos interferir o mínimo possível no contexto da sala de aula, na prática docente e na organização curricular da escola. As propostas de produção de texto em díades seguem estratégias didáticas já incorporadas no cotidiano desta instituição, assim como as leituras de textos literários fazem parte dos projetos didáticos por ela adotados. Nossa maior interferência deve-se, contudo, à presença de duas câmeras de vídeo, microfones e gravadores digitais, que eram dispostos na sala de aula de tal modo que pudessem registrar a aula dada e a interação de duas díades. Uma câmera registrava o processo de escritura em ato de uma díade de 
meninos, enquanto a outra registrava uma díade de meninas. Seguindo as instruçôes da professora, todos os alunos, em duplas, combinavam juntos uma história inventada e a escreviam em uma única folha de papel. Após estes materiais terem sido instalados, os pesquisadores retiravam-se da sala de aula e a professora trabalhava sozinha com seus alunos.

Neste artigo, iremos analisar o processo de criação do título presente no manuscrito produzido pela díade de meninos (Igor, 06:10 e Caio, 07:04) no dia 20 de abril de 2012, terceira proposta de produção de texto do projeto didático "Contos do como e do por que". Daremos destaque aos itens lexicais, semânticos e construçôes sintáticas relacionadas ao contexto letrado desses alunos e que emergem tanto no manuscrito escolar, quanto em seu processo de escritura. Recortamos alguns momentos deste processo, que denominamos "texto dialogal" (BRES, 2005), tendo como apoio para sua transcrição o programa Eudico Linguistic Annotator (Elan).

Contos etiológicos, figuras de texto e criação de títulos

Para que possamos analisar de que modo elementos advindos do contexto letrado podem estar presentes na nomeação de contos etiológicos e, de certo modo, nortear o processo de criação textual em sala de aula, tomaremos o processo de escritura do manuscrito "Como surgiu o ambiente e os animais", escrito pela díade Igor e Caio.

O título deste manuscrito lembra o conto "Como surgiu o mundo e (quase) tudo que tem nele" (ZATZ; ABREU, 2010), um dos que compunha o projeto didático que estava sendo trabalhado junto aos alunos, além de seu início "Como surgiu" remeter a uma explicação da origem das coisas, característica dos contos etiológicos. Estas aproximaçóes indicam o modo como as condições de produção são sustentadas pelo contexto letrado oferecido. Entretanto, o aparente imobilismo do título na folha de papel não deixa traços de seu processo escritural. Nada sabemos sobre como os alunos chegaram até ele: o que pensaram antes de escrevê-lo? Outro título foi proposto?

\section{Figuras de texto em título criado}

Responder a estas questões somente é possível através da recuperação do processo de escritura em ato. Após a professora ter proposto a produção 
de um conto de origem com "tema livre", explicar que o trabalho seria em díades e ter entregado a folha de papel com o cabeçalho, Igor e Caio se entreolham, estabelecendo o seguinte texto dialogal:

\section{Tabela 1}

Texto dialogal 1

\begin{tabular}{|c|c|c|c|}
\hline \multirow{3}{*}{$\begin{array}{l}\text { RUBRICA } \\
\text { 04:42 - 04:57 } \\
\text { Caio olhando para Igor } \\
\text { e sugerindo um tema. } \\
\text { Igor lembrando que fez } \\
\text { um "baú de histórias". } \\
\text { Professora entregando } \\
\text { uma caneta para o Caio, } \\
\text { que a pega e retira a } \\
\text { tampa. }\end{array}$} & \multicolumn{3}{|r|}{ DIÁLOGO } \\
\hline & $\begin{array}{c}\text { TC1 } \\
04: 42 \\
04: 45\end{array}$ & CAIO & $\begin{array}{l}\text { Vam-vam vamos fazer uma história sobre } \\
\text { animais? }\end{array}$ \\
\hline & $\begin{array}{c}\text { TC2 } \\
04: 46 \\
04: 50\end{array}$ & IGOR & $\begin{array}{l}\text { Eu ia fazer... sabe qual foi a história que } \\
\text { eu fiz lá? }\end{array}$ \\
\hline & $\begin{array}{c}\text { TC3 } \\
04: 50 \\
04: 50\end{array}$ & CAIO & Qual? \\
\hline & $\begin{array}{c}\text { TC4 } \\
04: 50 \\
04: 57\end{array}$ & IGOR & $\begin{array}{l}\text { Eu fiz baú de histórias... eu coloquei um } \\
\text { baú e um carro... pra lem... pra lembrar } \\
\text { do Scooby-Doo. Vocês. (Caio balançando } \\
\text { afirmativamente a cabeça, enquanto } \\
\text { está pegando a caneta que a professora } \\
\text { ofereceu). }\end{array}$ \\
\hline
\end{tabular}

"Uma história sobre animais" foi a primeira ideia que surgiu, dada por Caio. Com este enunciado, ele não só propõe um tema e personagem que caracterizam boa parte dos contos de origem escutados, mas também já apresenta o termo "animais" que será grafado no título.

Nos dois minutos subsequentes, os alunos escrevem seus nomes. Primeiro Caio escreve seu nome e o de Igor, mas ele mesmo rasura o "Igor", dando a caneta para o amigo e dizendo que é ele que deve escrever seu próprio nome. Depois disso, Caio, segundos antes de começar a escrever o nome da professora, é interrogado por Igor sobre o título, retomando assim o tópico iniciado no texto dialogal 1. 


\section{Tabela 2}

Texto dialogal 2

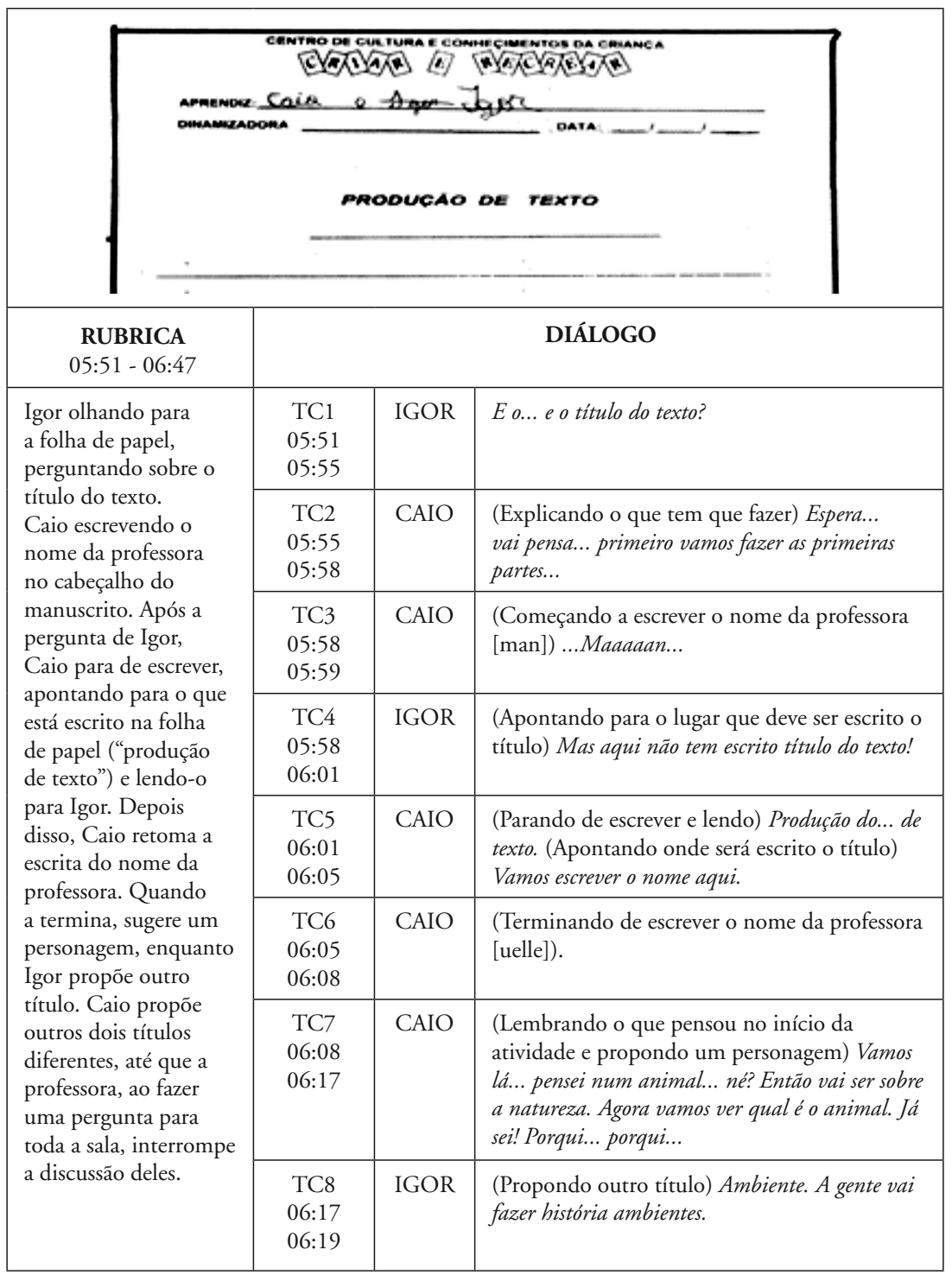




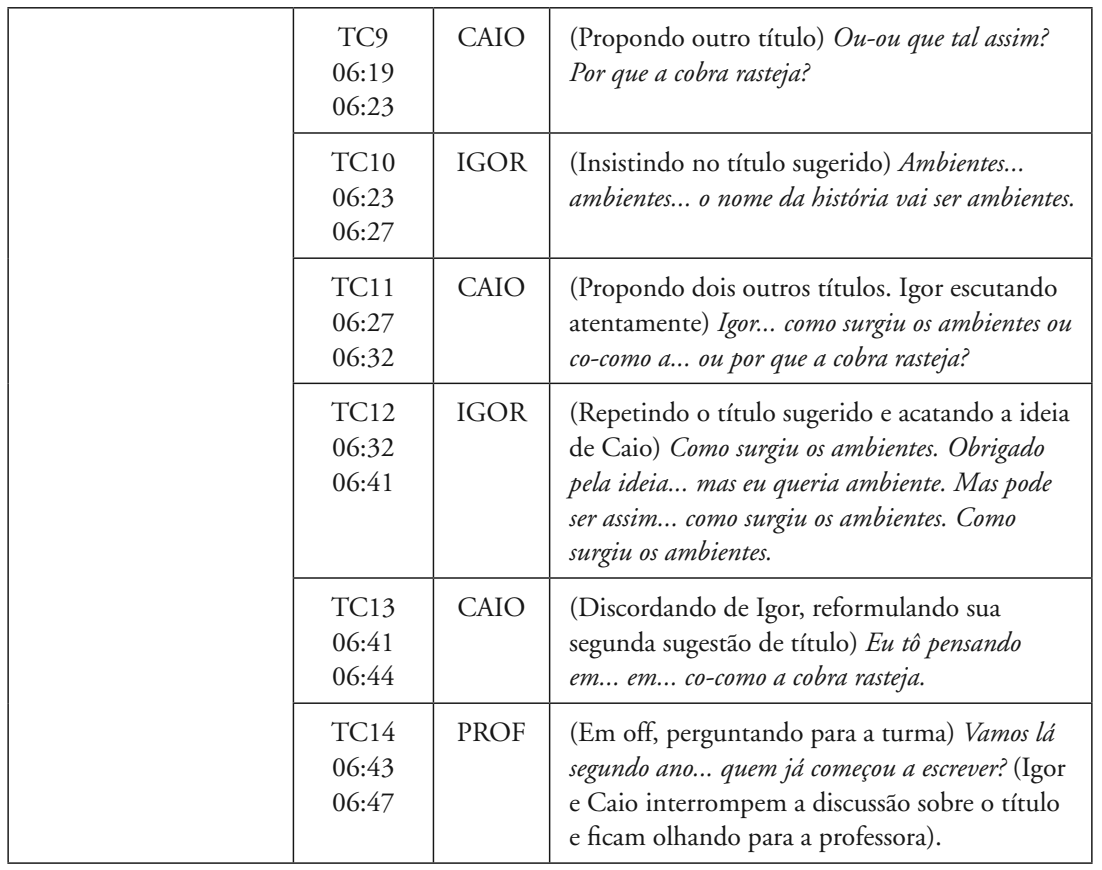

Igor, entre os 05:51 e 05:55, interroga seu parceiro sobre o título do texto, observando que ele ainda não estava escrito (TC4, 05:58 - 06:01). Caio, responsável por grafar o texto inventado e terminando de escrever o nome da professora no cabeçalho da folha, retoma sua ideia inicial de escrever sobre um animal ("pensei num animal... né?!"), associa-o ao termo "natureza" e tenta sugerir o nome de um animal para a história (TC7, 06:08 - 06:17). Parece ter sido a enunciação desta palavra que evocou em Igor os termos "ambiente" e "ambientes" (TC8, 06:17 - 06:19), distantes do léxico comum aos contos etiológicos, mas objeto de estudo da primeira unidade do livro didático de Ciências (MOTTA, 2010), trabalhada semanalmente durante os meses de março e abril.

Em sua primeira unidade, intitulada "Ambiente", o livro didático traz, entre os seus conteúdos, a "diversidade de ambientes, ambiente construído e ambiente natural; ambiente aquático e terrestre” (MOTTA, 2010, p. 8), enquanto as orientaçóes pedagógicas do "Projeto Ambiente, $2^{\circ}$ ano", 
elaboradas pela coordenação pedagógica da escola e entregue aos professores, visam a levar os alunos a "compreender a natureza como um todo dinâmico, sendo o ser humano parte integrante e agente de transformação do mundo em que vive" (ESCOLA CRIAR E RECREAR, 2012, p. 1).

Diante disso, podemos dizer que o sentido da palavra "natureza" dita por Caio não se limita aos animais que ele tenta propor para escrever o título do conto de origem inventado, como o faz quando diz "Ou-ou que tal assim? Por que a cobra rasteja?” (TC9, 06:19 - 06:23), título repetido ainda no TC11 e no TC13, com uma pequena variação ("Como a cobra rasteja"). "Natureza" parece ter sido a "palavra-chave" para que Igor fizesse outra relação associativa de ordem semântica, colocando na cadeia sintagmática o termo "ambientes". Termo incorporado pelo próprio Caio (TC11) e aceito por Igor entre os 06:32 - 06:41 (TC12), dentro da estrutura sintática "como surgiu X" que caracteriza os contos etiológicos conhecidos. O paralelismo sintático e semântico entre este título e o título do primeiro conto lido para os alunos ("Como surgiu o mundo e [quase] tudo o que tem nele") é evidente, mas não é, como o diálogo indica, intencional ou premeditado. Do mesmo modo, encontramos semelhanças com outros títulos dos contos do livro De onde tudo surgin e como tudo começou (tudo, tudo mesmo!) (ZATZ; ABREU, 2010): "Como surgiram os morcegos", "Como surgiram as línguas". Estas relaçōes paralelísticas, e o que elas trazem de repetição, seja sintática, seja semântica, podem ser tomadas como efeitos da alteridade constituída pela interação verbal, assim como fazem parte do processo de apropriação do gênero pelos alunos. Em outras palavras, sem as práticas discursivas mediadas através do gênero textual eleito, dificilmente os alunos poderiam se apropriar de suas características.

Entretanto, como vimos, o título final do manuscrito ainda não foi "Como surgiu os ambientes" [sic]. A díade coloca a data e somente aos $07: 38$ é que começam a escrever o título, como o texto dialogal 3 descreve.

O título final, depois de um percurso certamente imprevisível, recursivo e não linear, foi escrito por Caio entre os 07:56 e 08:41. Ele retoma o que foi dito pela primeira vez, logo no início do texto dialogal 1, aos 04:42 (Vam-vam vamos fazer uma história sobre animais?), ajustando este tema ao termo "ambiente" sugerido por Igor, aos 06:17 (Ambiente. A gente vai fazer história ambientes.). 


\section{Tabela 3}

Texto dialogal 3

\begin{tabular}{|c|c|c|c|}
\hline \multirow[t]{2}{*}{ 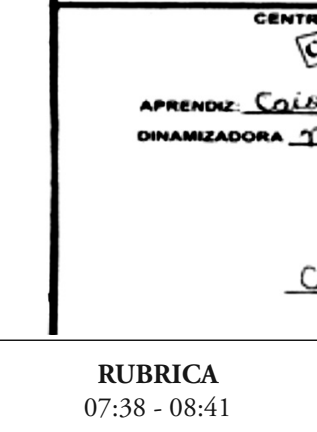 } & 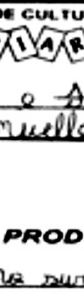 & 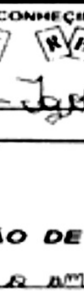 & 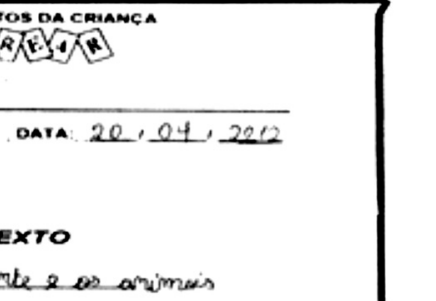 \\
\hline & & & DIÁLOGO \\
\hline \multirow{7}{*}{$\begin{array}{l}\text { Enquanto a professora } \\
\text { relembra aos alunos que } \\
\text { irão escrever um conto de } \\
\text { origem inventado, Caio, } \\
\text { tocando no braço de Igor } \\
\text { para chamar sua atenção, } \\
\text { propõe um novo título. } \\
\text { Igor, olhando para Caio, } \\
\text { insiste no título que } \\
\text { sugeriu anteriormente. } \\
\text { Caio propōe novamente } \\
\text { outro título, que será } \\
\text { aceito por Igor. } \\
\text { Caio começa a escrever } \\
\text { o título que acabou de } \\
\text { sugerir. Enquanto Caio } \\
\text { está escrevendo, Igor } \\
\text { sugere uma pequena } \\
\text { alteração, mas Caio a nega. } \\
\text { Depois disso, Igor propõe } \\
\text { ainda outra mudança } \\
\text { que também não é aceita } \\
\text { por Caio. Caio termina } \\
\text { por escrever o título da } \\
\text { história. }\end{array}$} & $\begin{array}{l}\text { TC1 } \\
07: 38 \\
07: 46\end{array}$ & CAIO & $\begin{array}{l}\text { (Falando para si mesmo) Pensei em outro. } \\
\text { (Tocando no braço do amigo) Igor! } \\
\text { (Igor olhando para Caio) Gostou dessa? } \\
\text { Co-como... ééé... surgiu os animais? }\end{array}$ \\
\hline & $\begin{array}{l}\text { TC2 } \\
07: 46 \\
07: 48\end{array}$ & IGOR & Como surgiu os ambientes! \\
\hline & $\begin{array}{c}\text { TC3 } \\
07: 48 \\
07: 50\end{array}$ & \multicolumn{2}{|c|}{ (Caio e Igor se entreolhando em silêncio). } \\
\hline & $\begin{array}{c}\text { TC4 } \\
07: 50 \\
07: 52\end{array}$ & CAIO & Que tal os ambientes e os animais? \\
\hline & $\begin{array}{l}\text { TC5 } \\
07: 52 \\
07: 56\end{array}$ & IGOR & $\begin{array}{l}\text { (Concordando) Isso! Como surgiu o... os } \\
\text { ambientes e os animais. }\end{array}$ \\
\hline & $\begin{array}{l}\text { TC6 } \\
07: 56 \\
08: 00\end{array}$ & CAIO & $\begin{array}{l}\text { (Escrevendo) ....coooo }[\mathrm{co}] \ldots . \\
m o o o[\mathrm{mo}] \ldots\end{array}$ \\
\hline & $\begin{array}{c}\text { TC7 } \\
08: 00 \\
08: 04\end{array}$ & CAIO & $\begin{array}{l}\text { (Em silêncio, continuando a escrever } \\
\text { [surgiu]). }\end{array}$ \\
\hline & $\begin{array}{c}\text { TC8 } \\
08: 00 \\
08: 04\end{array}$ & IGOR & $\begin{array}{l}\text { (Falando enquanto Caio escreve) Mas... } \\
\text { primeiro quem vai começar a existir... vai } \\
\text { ser os animais. }\end{array}$ \\
\hline
\end{tabular}




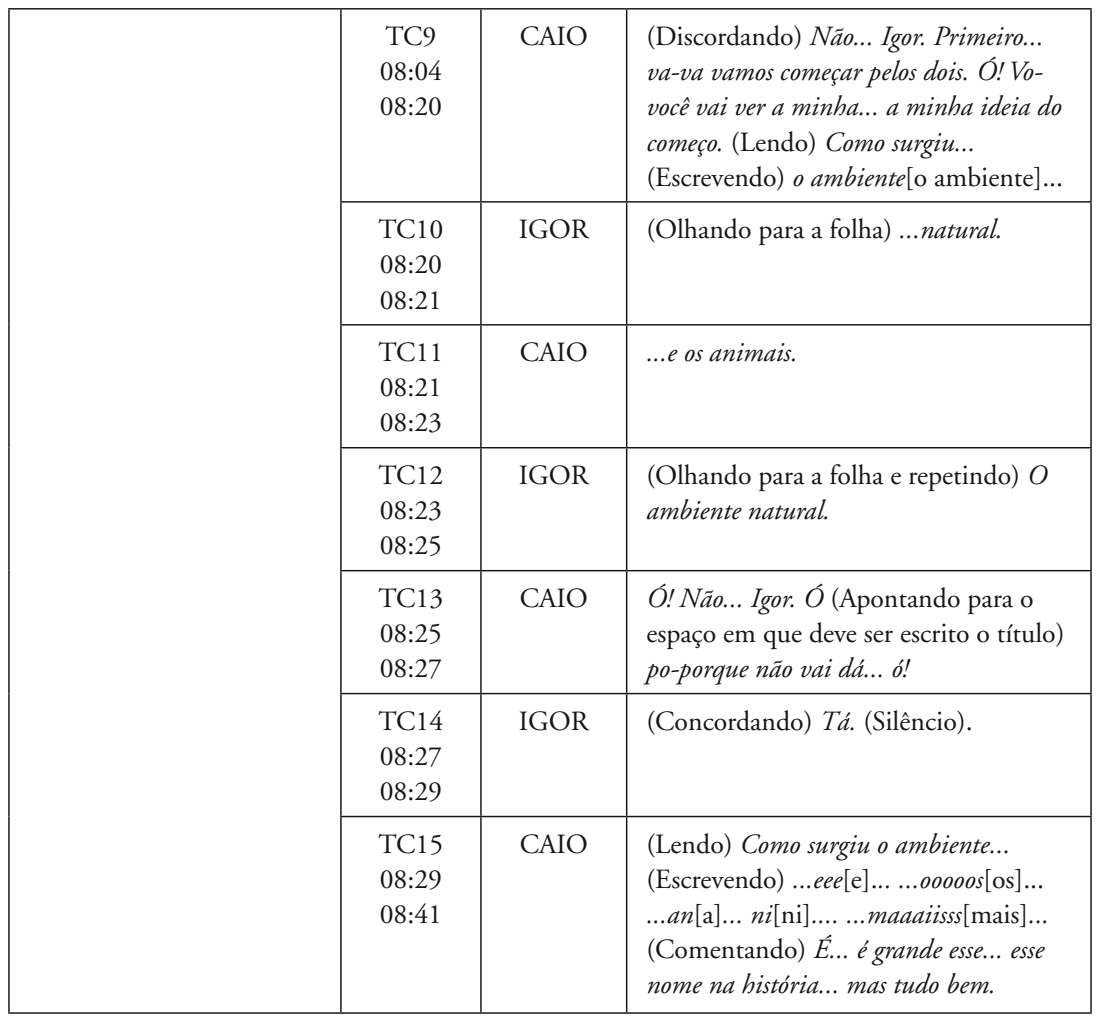

Contudo, neste texto dialogal 3, surge um elemento novo, enunciado por Igor entre 8:20 - 8:22 (TC10), que será mais um índice da efetiva interferência do livro didático de Ciências no processo de criação desses alunos. Ao adjetivar o "ambiente", inserindo o termo "natural", ele recupera uma informação fornecida por este livro, como exemplifica o texto "Ambientes naturais e construídos" (MOTTA, 2010, p. 14) e a discussão que realiza.

O fato de Caio ter recusado (TC13) a entrada de "natural", argumentando que não daria para escrever porque o título já estava maior do que a linha indicando seu lugar na folha de papel, não quer dizer que o enunciado de Igor não produziu efeito sobre a história que estava sendo inventada. O fragmento abaixo do manuscrito dos alunos mostra claramente isso: 


\section{Figura 1}

Fragmento do manuscrito "Como surgiu os animais e o ambiente", linhas 9 e 10.

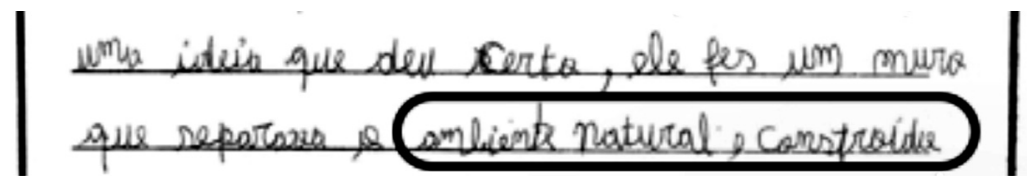

A entrada de termos advindos dos textos que constam no livro didático de Ciências, no processo de escritura e criação de um conto etiológico e seu registro no manuscrito final dos alunos, tem, ao menos, dois pontos importantes a serem destacados:

1. Indica que o contexto letrado, em que circulam de modo significativo bons textos literários e bons livros didáticos, oferece material linguístico-discursivo para o processo de criação dos alunos.

2. Revela a qualidade da prática didática desta escola, em particular, da didática de escrita, por meio da qual o aluno poderá constituir sua posição enunciativa como escrevente, apropriando-se de modo singular e letrado das características do gênero eleito.

\section{Conclusão}

Procuramos mostrar, a partir da análise do processo de escritura de um título em sala de aula, de que modo o letramento escolar interfere na criação textual de alunos recém-alfabetizados. De maneira geral, podemos dizer que as relações de alteridade constituídas pela transmissão e práticas discursivas envolvendo tanto o gênero eleito para produção de texto (contos etiológicos), quanto outros (no caso analisado, os textos relacionados ao conteúdo de Ciências Naturais), terão por função contribuir para a formação do aluno como escrevente. De um lado, a repetição de textos de um mesmo gênero favorece a formação de uma memória de longo termo, oferecendo um suporte para a configuração do título do manuscrito de Caio e Igor, conforme observamos na presença da estrutura 
"Como surgiu x". De outrolado, o trabalho com o material disponível no livro didático de Ciências faz parte, igualmente, do processo de geração do título deste manuscrito.

Defendemos, por fim, que a compreensão do que se passa no tempo real de uma escritura pode nos ajudar a entender de que modo o letramento escolar interfere em seu processo, mas também como alunos recém-alfabetizados se apropriam, durante esse processo, de conhecimentos almejados pela escola. Entretanto, ainda temos poucos estudos sobre processos de escritura a dois na sala de aula que nos assegurem a importância desta prática didática para o redimensionamento da criação textual e da relação entre o escrevente novato e o texto em curso.

\section{Notas}

1. Agradecemos à equipe pedagógica da Escola Criar e Recrear, em particular à coordenadora pedagógica e à professora do $2^{\circ}$ ano e seus alunos, pela participação e pelo envolvimento dedicados durante a realização deste estudo.

2. TC significa o tempo cronometrado e registrado a partir do momento em que a filmadora foi acionada. Ou seja, neste caso, o diálogo entre Caio e Igor transcrito no texto dialogal 1, indicado por esta tabela, ocorreu entre os 04:42 (quatro minutos e quarenta e dois segundos) e 04:57 (quatro minutos e cinquenta e sete segundos). Esta informação é fornecida pelo programa Elan.

\section{Referências}

AMORIM, M. Memória do objeto: uma transposição bakhtiniana e algumas questões para a educação. Bakhtiniana, São Paulo, v. 1, n. 1, p. 08-22, 2009.

BAKHTIN, M. Estética da criação verbal. São Paulo: Martins Fontes, 1992. BEREITER, C.; SCARDAMALIA, M. The psychology of written composition. Hilsdale: Lawrence Erlbaum, 1987.

BRAGUINHA, J.B. Festa no céu. Rio de Janeiro: JPA, 2009.

BRASIL. Ministério da Educação. Secretaria de Ensino Fundamental. Parâmetros Curriculares Nacionais: Língua Portuguesa $1^{\text {a }}$ a $4^{\mathrm{a}}$ séries. Brasília, DF, 1997. v. 2. 
BRASIL. Ministério da Educação.Secretaria de Educação Básica. Secretaria de Educação a Distância. Programa de Formação Continuada de Professores das Séries Iniciais do Ensino Fundamental: pró-letramento. Brasília, DF, 2007a.

BRASIL. Ministério da Educação. Secretaria de Educação Básica. Fundo Nacional de Desenvolvimento da Educação. Diretoria de Assistência a Programas Especiais. Programa de Apoio a Leitura e Escrita: Praler. Brasília, DF, 2007b.

BRES, J. Savoir de quoi on parle: dialogue, dialogal, dialogique. In: BRÉS, J. et. al. (Org.). Dialogisme, polyphonie: approches linguistiques. Paris: De Boeck, 2005. p. 47-61.

CALIL, E. Escutar o invisivel: a escritura e poesia na sala de aula. São Paulo: Unesp; Rio de Janeiro: Funarte, 2008.

CALIL, E. Autoria: a criança e a escrita de histórias inventadas. 2. ed. Londrina: Eduel, 2009.

CALIL, E. A menina dos títulos: repetição e paralelismo em manuscritos de Isabel. Alfa, São Paulo, v. 54, n. 2, p. 533-564, 2010.

CALIL, E. A rainha comilona: dialogismo e memória na escritura escolar. Bakhtiniana, São Paulo, v. 7, n. 1, p. 24-45, jan./jun. 2012a.

CALIL, E. Rasuras orais em madrasta e as duas irmãs: processo de escritura de uma díade recém-alfabetizada. Educação \& Pesquisa, São Paulo, v. 38, n. 3, p. 589-602, jul./set. 2012b.

DUFOUR, D.-R. Les mystères de la Trinité. Paris: Gallimard, 1990.

DUFOUR, D.-R. A arte de reduzir as cabeças: sobre a nova servidão na sociedade ultraliberal. Rio de Janeiro: Cia de Freud, 2005.

ESCOLA CRIAR E RECREAR. Projeto Ambientes: $2^{\circ}$ ano do ensino fundamental. 2012.

GARCEZ, L.H.C. A escrita e o outro: os modos de participação na construção do texto. Brasília, DF: UnB, 1998.

GERALDI, J.W. (Org.). O texto na sala de aula: leitura e produção. Cascavel: Assoeste, 1984. 
KELLOGG, R.T. Training writing skills: a cognitive developmental perspective. Journal of Writing Research, Antwerpen, v. 1, n. 1, p. 1-26, 2008. KLEIMAN, A. et al. Os significados do letramento: uma nova perspectiva sobre a prática social da escrita. Campinas: Mercado de Letras, 1995.

MATENCIO, M.L.M. Leitura, produção de textos e a escola: reflexões sobre o processo de letramento. Campinas: Mercado de Letras, 1994.

MCCUTCHEN, D. Knowledge, processing, and working memory: implications for a theory of writing. Educational Psychologist, Hillsdale, v. 35, n. 1, p. 13-23, 2000.

MCCUTCHEN, D. From novice to expert: implications of language skills and writing-relevant knowledge for memory in the development of writing skill. Journal of Writing Research, Antwerpen, v. 3, n. 1, p. 51-68, 2011.

MOTTA, C. Aprender juntos Ciências, 20 ano. São Paulo: SM, 2010.

ROJO, R. (Org.). Alfabetização e letramento: perspectivas linguísticas. Campinas: Mercado de Letras, 1998.

SAUTCHUK, I. A produção dialógica do texto escrito: um diálogo entre escritor e leitor interno. São Paulo: Martins Fontes, 2003.

SOARES, M. Alfabetização e letramento. São Paulo: Contexto, 2004.

ZATS, L.; ABREU, G. De onde tudo surgiu e como tudo começou (Tudo, tudo mesmo!'). São Paulo: Moderna, 2010.

Recebido em 30 de setembro de 2012.

Aprovado em $1^{\circ}$ de março de 2013.

Cad. Cedes, Campinas, v. 33, n. 89, p. 73-89, jan.-abr. 2013 